\title{
Photoinduced Electron- and Energy-Transfer Processes in Supramolecules using Imide Compounds
}

\author{
Mamoru Fujitsuka* and Tetsuro Majima* \\ The Institute of Scientific and Industrial Research (SANKEN), Osaka University, Mihogaoka 8-1, Ibaraki, Osaka \\ 567-0047, Japan
}

\begin{abstract}
We summarize recent studies on photoinduced electron- and energy-transfer processes of various supramolecules including imide group(s) as a component. Recently, imides have been employed in various functional molecular systems, because of their excellent photophysical and electron accepting properties. Our research group also employed imides in various supramolecular systems such as donor-acceptor dyads, quantum dots, DNA, and so on. First, we summarize fundamental properties of imides such as photophysical and electrochemical properties. Then, photoinduced processes of imides in the supramolecular systems are described to show their applicability in the various fields.
\end{abstract}

\section{Introduction}

In many scientific fields, electron transfer and energy transfer processes are important mechanical basis. Although the theories for these processes were already established, the number of the studies on these processes is still increasing. Various photoinduced processes related to the natural photosynthesis systems have attracted quite wide attentions of scientists for long time and their mechanisms have been revealed by various spectroscopic measurements including ultrafast spectroscopy. ${ }^{1}$ The studies trying to mimic the natural photosynthesis realized various artificial photosynthesis systems which are applicable to light-energy conversion systems such as solar cells. In addition, organic synthesis initiated by photoinduced electron transfer and energy transfer has been also investigated widely to attain efficient and selective reactions. Photocatalyst should be one of the successful fields which include photoinduced electron

*To whom correspondence should be addressed.

E-mail: majima@sanken.osaka-u.ac.jp transfer and energy transfer as a key mechanism. Nowadays, scientists in the fields of DNA, protein, medicine, and so on have also showed great activities in the research fields related to electron transfer and energy transfer. Photo dynamic therapy and bio-sensor should be the successful examples of such activities.

Until the 1990s, studies on electron transfer and energy transfer were carried out using porphyrins, quinones, viologens, and so on as key pigments. $^{2-3}$ Fullerenes have been used in these studies from around 2000. ${ }^{4}$ These compounds have been selected because of their favorite characteristics for application such as absorption, fluorescence, and redox properties. $^{2-4}$ Recently, various imide compounds (Figure 1) such as naphthalimide (NI) and perylenediimide (PDI) have been employed as components of photofunctional molecular systems very frequently, while pyromellitimide (PI) had been employed as a counter part of porphyrin derivatives. ${ }^{5}$ Their rigid structures and organic chemically well-established functionalization methods are parts of the reasons why these imides are often employed as a building block of the molecular systems. The poor solubility of these imides in various solvents, which made applications limited previously, can be overcome by introduction of various substituents. Nowadays, solubility to aqueous media is also realized. ${ }^{6}$ From these enhanced versatility as a component of supramolecules, various researchers pay much attentions to imide compounds.

In the present review, we summarize characteristics of supramolecules using imide compound(s) as a component. First, characteristics of imide compounds useful for the study of energy- and/or electron transfer aiming at efficient photo-energy conversion systems 
are summarized. Then, recent studies on supramolecules including ours will be introduced.

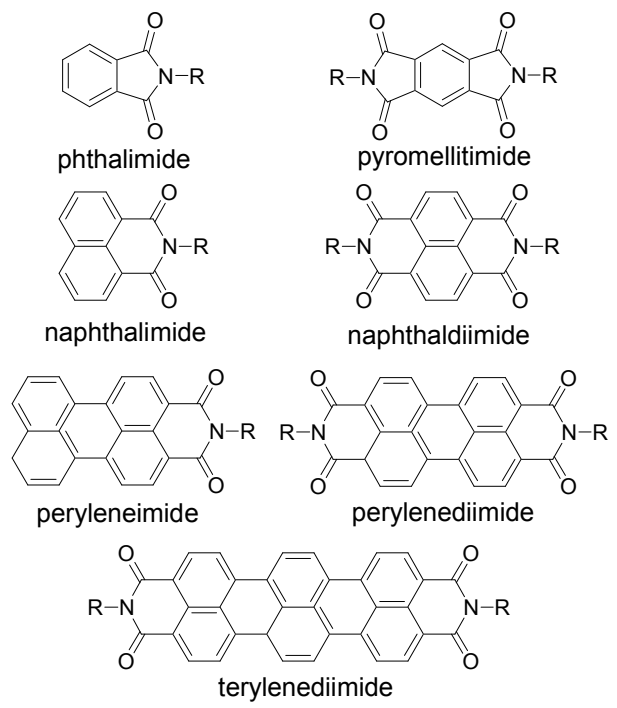

Figure 1. Molecular structures of imides

\section{Characteristics of imide compounds}

One of the important characteristics of imides should be large photon absorption ability in the wide spectral regions ranging from $\mathrm{UV}$ to near-IR, ${ }^{7}$ which can be controlled by structural factors such as size of $\pi$ -conjugation, torsional angle, ${ }^{8}$ and intramolecular CT character. ${ }^{9}$ In the case of PDI, it was reported that introduction of the substituent, which induces intramolecular CT character to PDI, shifted the absorption peak position to $700 \mathrm{~nm},{ }^{10}$ while the absorption peak of the pristine PDI is $526 \mathrm{~nm}$. The large absorption band ranging from UV to near-IR regions is a favorite character for the application to light-energy conversion systems which can be used in solar cell application. ${ }^{11-12}$

As expected from the large absorption of these compounds, large fluorescence quantum yields are reported for these imides. For example, the fluorescence quantum yields of PDI and terylenediimide (TDI) are reported to be 0.98 and 0.9 , respectively. ${ }^{13-14}$ High fluorescence quantum yields and the peak positions of these imides in the visible region (550 and $670 \mathrm{~nm}$, respectively) facilitate utilization of these imides as fluorescence probe of biomolecules and single molecule fluorescence spectroscopy studies. In the case of NI, it has been reported that the existence of $\mathrm{T}_{2}$ state, which is energetically close to $S_{1}$ state, enhances the intersystem crossing rate resulting in low fluorescence quantum yield. ${ }^{15}$

Another important characteristic of imide compounds is higher electron-accepting ability. Especially, electron acceptor ability of their excited state is useful for various purposes including donor-acceptor molecular systems mimicking the natural photosynthesis systems. Table 1 summarizes the first and second reduction potentials of imide compounds. ${ }^{7}$ Since the reduction potentials of $p$-benzoquinone and methylviologen, which are important electron acceptors in the field of artificial photosynthesis, are -0.51 and $-0.45 \mathrm{~V}$ vs. $\mathrm{SCE}^{3}$ the reduction potentials of imides cover the potential range useful for study of light-energy conversion systems. Additionally, sharp and large absorption bands of the reduced imides are useful in the observation of photoinduced process by means of transient absorption spectroscopy. ${ }^{7,16-17}$ This is another reason why the imides have been employed in various photofunctional molecules. As indicated in this section, imide compounds are useful for the study of energyand/or electron transfer aiming at efficient photo-energy conversion systems.

Table 1. Redox potentials of imides (vs. SCE). ${ }^{7}$

\begin{tabular}{lcc}
\hline & $E_{1 / 2}\left(\mathrm{~A}^{\bullet} / \mathrm{A}\right)$ & $E_{1 / 2}\left(\mathrm{~A}^{2-} / \mathrm{A}^{\bullet}\right)$ \\
\hline phthalimide $^{\mathrm{a}}$ & -1.40 & -2.30 \\
pyromellitimide $^{\mathrm{a}}$ & -1.365 & \\
naphthalimide $^{\mathrm{a}}$ & -0.96 & -1.55 \\
naphthaldiimide $^{\mathrm{a}}$ & -0.71 & -1.37 \\
peryleneimide $^{\mathrm{a}}$ & -0.48 & -0.99 \\
perylenediimide $^{\mathrm{a}}$ & -0.43 & -0.70 \\
\hline
\end{tabular}

${ }^{\mathrm{a}}$ Substituent(s) at the $\mathrm{N}$ position(s) is 2,5-di-tert-butylphenyl.

\section{Emission properties of organized imides}

As indicated in the previous section, one of the characteristics of imide comnounds is the hioh fluorescence quantum yield. Especially imides with highly developed $\pi$-conjugation systems tend to exhibit quantum yield close to unity, ${ }^{13-14}$ which is useful in application such a $\mathrm{s}$ a fluorescence probe. ${ }^{18}$ In this section, we want to ov erview the emission properties of structurally organiz-ed imides, such as aggregate and stacked dimers.

\subsection{Aggregates of imides}

It has been reported that imides such as PDI form various types of aggregate depending on conditions 
such as solvent and temperature. ${ }^{19}$ For example, PDI tends to form H-type aggregate, of which fluorescence showed longer wavelength shift and broadening compared to those of PDI monomer. Wasielewski and his coworkers reported fluorescence properties of cofacial PDI dimer which was prepared by connecting two PDIs to 4,5-positions of xanthene. ${ }^{20}$ The c ofacial dimer showed a fluorescence peak at $735 \mathrm{~nm}$ while that of monomer is $535 \mathrm{~nm}$, indicating the extensive longer wavelength shift due to excitonic coupling of the transition dipole of PDI which is aligned along the long axis of PDI monomer. Furthermore, they investigated structural relaxation upon laser excitation by transient absorption spectroscopy of the excimer state of the compounds.

Although PDI tends to form $\mathrm{H}$-aggregate as indicated above, this tendency can be controlled by introduction of substituents to PDI. It was reported that PDI can form J-aggregate, when PDI has bulky substituents at 1,6,7,12-positions. ${ }^{8}$ Yagai et al. reported that formation of hydrogen bonding between $\mathrm{OH}$ groups attached to PDI and cyanurate can control formation of $\mathrm{H}$ - and Jaggregates. $^{21}$ They observed that $\mathrm{H}$-aggregate showed an excimer-like fluorescence with a peak at $636 \mathrm{~nm}$, while J-aggregate showed that with a peak at $673 \mathrm{~nm}$. 3.2 Excimer of imides

Excimer emission of chromophores is efficiently generated when chromophores are linked by chemical bond such as an alkyl chain. Especially, connection by a propyl chain enhances excimer formation as known as the " $n=3$ rule". ${ }^{22}$ We investigated the emission properties of NI dimers connected by an alkyl chain $\left(\mathrm{NI}-\mathrm{C}_{\mathrm{n}} \mathrm{H}_{2 \mathrm{n}}-\mathrm{NI}\right){ }^{23}$ These compounds showed similar absorption spectra with that of the monomeric compound. On the other hand, the dimeric compounds showed the excimer emission around 425-491 $\mathrm{nm}$ as well as monomer emission at $370 \mathrm{~nm}$, indicating that excimer is formed by dynamic motion of the alkyl chain in the excited state. The lifetime of the monomeric fluorescence was 100-200 ps, indicating the excimer formation in the sub-nanosecond time region. With the increase in the length of the alkyl chain connecting two NIs, the peak position of the excimer emission band shifted to shorter wavelength side accompanying reduction of quantum yield, indicating un-stabilization of excimer with an increase in the length of the alkyl chain due to longer chromophore distance and un-favorite orientation for the excimer formation. Furthermore, in the solvent containing water, further longer wavelength side shift was observed due to the formation of the hydrogen bond between water and the carbonyl group of NI.

\subsection{Exciplex of imides}

When imide is connected with an electron donor molecule via an adequate linker, photoinduced electron transfer process is expected as discussed in the next section. Under the condition where electron transfer is not preferential process, exciplex emission will appear. We reported the observation of clear exciplex emission from the donor-acceptor dyad molecules of NI and phenothiazine (PTZ), which acts as the electron donor, connected by an alkyl or ethylether chain (NI-C-PTZ or NI-O-PTZ, respectively). ${ }^{24}$ The emission spectra of the dyad molecule in $n$-hexane showed three emission bands designated as SW $(\sim 370 \mathrm{~nm})$, MW $(\sim 425 \mathrm{~nm})$, and LW ( $\sim 600 \mathrm{~nm})$ (Figure 2$)$. SW can be attributed to the monomer fluorescence, while $\mathrm{MW}$ is the excimer emission due to intermolecular excimer format ion, i.e. ${ }^{1}(\mathrm{NI}: \mathrm{NI})^{*}$ from the similarity in the spectral shape and the wavelength region with the above discussed $\mathrm{NI}-\mathrm{C}_{\mathrm{n}} \mathrm{H}_{2 n}-\mathrm{NI}$. The LW can be attributed to the intramolecular exciplex emission because LW was not observed with the monomeric NI compound without PTZ. The formation process of the exciplex structure can be followed by the rising fluorescence profile of the LW band. The rising kinetic profile of the LW emission can be analyzed by multi-components rise function, indicating the existence of various conformers in solution due to the flexible alkyl chain connecting NI and PTZ.
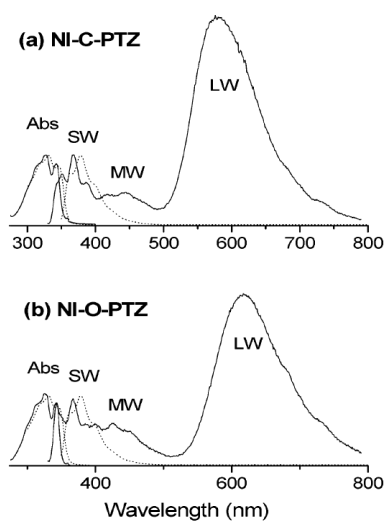

Figure 2. Emission spectra of NI-C-PTZ and NI-O-PTZ in $n$-hexane. Reprinted with permission from ref. 24. Copyright (2006) American Chemical Society

When molecules with donor-ability are contained in the solvent, exciplex formation between NI and donor-character molecules is expected. This 
phenomenon was observed with NI molecule in solvent including methylated benzene. It became clear that the peak position of the exciplex band largely depends on the donor ability of the methylated benzene. $^{25}$

\subsection{Application to single molecular detection of reactive oxygen species}

At the end of this section, we introduce an example which applied strongly emissive nature of imide compounds to evaluation of reactivity of reactive oxygen species. Reactive oxygen species including singlet oxygen and hydroxyl radical, which can be generated by photo-irradiation to photocatalyst, can transport in air to react with a substrate at distance as known as the remote oxidation process. ${ }^{26}$ Because of quite small amount of these reactive species, detection and analysis of these species are quite difficult subject. Based on the fact that diepoxide of TDI, which is a reaction product of TDI and singlet oxygen, shows strong emission in the shorter wavelength side compared to that of the pristine TDI, we applied single molecule spectroscopy to this subject aiming at clarification of the generation process of the singlet oxygen and its transport property. In the experiment, $\mathrm{TiO}_{2}$ film prepared on a slide glass and a cover glass, on which TDI was dispersed, were placed with the controlled distance as shown in Figure 3. Upon UV light irradiation to the $\mathrm{TiO}_{2}$ film, fluorescence spots due to the formation of TDI diepoxide were confirmed, indicating the singlet oxygen generated on $\mathrm{TiO}_{2}$ film transported to TDI via the gap. From the distance dependence, the transport rate and generation yield of singlet oxygen were successfully evaluated. ${ }^{27}$

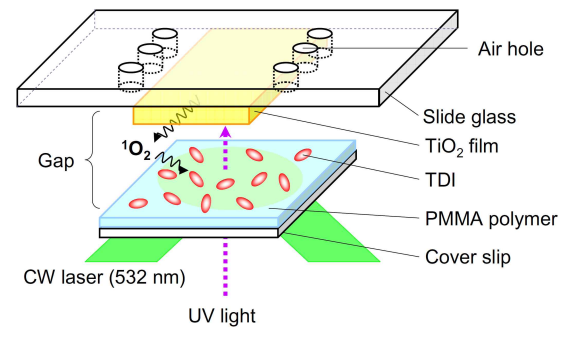

Figure 3. Schematic representation of experimental setup: single molecule fluorescence measurement during the $\mathrm{TiO}_{2}$ photocatalytic reaction. Reprinted with permission fromref. 27. Copyright(2006) American Chemical Society

As indicated in this section, fluorescence characteristics of imide compounds such as high fluorescence yield and large spectral change upon complex or aggregate formation are quite useful for monitoring structure of flexible molecular systems including the biomolecular systems. Furthermore, stability of imide compounds under photoirradiation is also useful for the detection of the photo reaction with single molecular level. These applications based on the fluorescence properties of imides will be investigated quite widely.

\section{Donor-acceptor dyad molecules using imides}

As indicated in the introduction, various imides exhibit good electron acceptor ability, which is useful in the study of electron transfer systems such as donor-acceptor dyad. Especially, the group of Wasielewski and the group of Würthner have reported synthesis and properties of various supramolecular donor-acceptor systems until now. ${ }^{5,28-30}$ Our research group also applied imides to various molecular systems including supramolecular system and DNA conjugate. $^{31-32}$ Here, we summarize these studies on the electron transfer process in the supramolecular systems using imides.

\subsection{Electron transfer in covalently linked donor-acceptor molecule}

For application to efficient light-energy conversion, strong absorption covering the spectrum of solar light is preferable property of donor-acceptor dyads. From this viewpoint, PDI with a large absorption with peaks around $550 \mathrm{~nm}$ is an ideal molecule, although absorption around $300-480 \mathrm{~nm}$ is rather weak. Thus, the donor molecule that covers this wavelength region is useful as a partner of PDI. One of the candidates will be oligothiophenes, because they exhibit large absorption in the above mentioned region. From this point, we studied photoinduced electron transfer process in covalently linked dyad molecules of oligothiophene, a pentamer of thiophene (5T), and PDI, which were connected by a propyl (C3) or hexyl (C6) linker to reveal the conformation effect on the photoinduced processes. ${ }^{33}$

By using 550-nm femtosecond laser pulse for the excitation of $\mathrm{C} 3$ or $\mathrm{C} 6$, photoinduced process originated from PDI in the singlet excited state can be investigated (Figure 4). The quantitative charge separation via PDI in the singlet excited state was confirmed in various solvents such as toluene, anisole, and benzonitrile. The lifetime of the charge separated 
state was calculated to be $7.1 \mathrm{~ns}$ for $\mathrm{C} 6$ in toluene, although the lifetime of the charge separated state depends on solvent polarity and linker length. By using 400-nm laser for the excitation of the dyads, photoinduced process via $5 \mathrm{~T}$ in the singlet excited state can be examined. It was revealed that $5 \mathrm{~T}$ in the singlet excited state deactivated within $\sim 1$ ps and PDI in the singlet excited state was generated, indicating the efficient singlet energy transfer from 5T to PDI. From PDI in the singlet excited state generated by the energy transfer from 5T, charge separation was confirmed, of which dynamics were the same as those observed with the 550-nm laser excitation of the dyads. These findings indicate that the charge separation from PDI in the singlet excited state can be realized independent of the excitation wavelength like photo energy harvesting functionality in the natural photosynthesis systems. From the comparison of the distance dependence of the observed energy and electron transfer rates with those expected from Förster and Marcus theories, respectively, it was revealed that these dyad molecules tend to form folded conformer in solvent, which makes the distance between the 5T and PDI rather short.

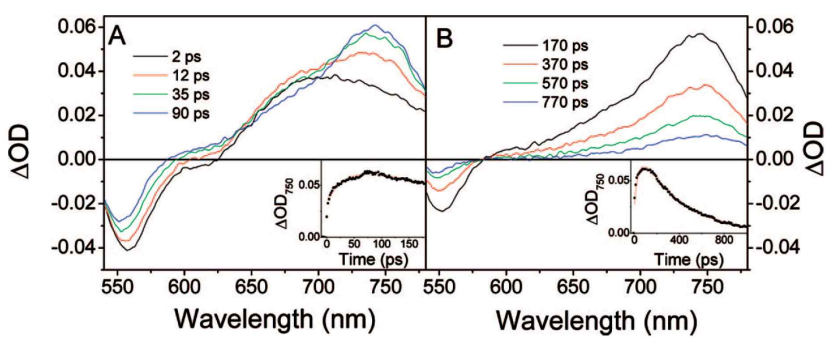

Figure 4. Transient absorption spectra observed during the laser flash photolysis of 5T-PDI (C3) in toluene using 550-nm femtosecond pulse. Reprinted with permission from ref. 33. Copyright (2008) American Chemical Society.

When the NI moiety of NI-PTZ dyads, which are introduced in the previous section, was excited using the 355-nm picosecond laser in acetonitrile, transient absorption bands attributable to the radical anion of NI and the radical cation of PTZ were observed at 420 and $520 \mathrm{~nm}$, respectively. ${ }^{34}$ The generation rate of the radical ion pair was slower than the fluorescence decay rate, indicating the contribution of the triplet excited state in the charge separation process as well as the singlet excited state. The charge separated state was also confirmed during the laser flash photolysis using the nanosecond laser, and the lifetime of the charge separated state was determined to be $3.8 \mu \mathrm{s}$. On the other hand, in toluene, non-polar solvent, charge separation occurred only from NI in the singlet excited state, not from NI in the triplet excited state, indicating that unstabilization of the charge separated state in non-polar solvent made the charge separation from the triplet excited state the endothermic process.

Additionally, photoinduced electron transfer processes of NI-PTZ dyad molecules were examined in water/acetonitrile media. ${ }^{35}$ The intramolecular electron transfer from NI in the singlet excited was suggested from the fluorescence quantum yield and lifetimes which were smaller than those of NI. In the case of NI-PTZ dyad connected by a C8 linker, the charge separation rate was $6.6 \times 10^{9} \mathrm{~s}^{-1}$, while the lifetime was $18 \mu \mathrm{s}$. It should be noted that in water/acetonitrile solvent, formation of $\mathrm{NI}^{\circ}$ and $\mathrm{NI}^{-}$ pair from ${ }^{3} \mathrm{NI}{ }^{*}$ and NI occurred efficiently. It was also suggested that, in protic polar solvents, $\mathrm{NI}^{-}$ easily formed a ketyl radical $\left(\mathrm{NIH}^{\circ}\right)$ by hydrogen abstraction from $\mathrm{H}_{2} \mathrm{O}$, and showed a transient absorption band around $410 \mathrm{~nm}$.

In water/acetonitrile solvent, the effect of cyclodextrin (CD), which prevents formation of excimer or exciplex-like excited state, on photoinduced processes was also investigated. ${ }^{36}$ Photoinduced electron transfer in NI- PTZ led to $\mathrm{NI}^{\circ}$ and $\mathrm{PTZ}^{\circ+}$ from the $T_{1}$ state. The charge recombination time of the transient species at $400 \mathrm{~nm}$ showed a strong dependency on the size of $\mathrm{CD}$ : the charge recombination time of the dyad in $\gamma_{-} \mathrm{CD}$ was increased markedly than that in $\beta$-CD. This suggests that the PTZ moiety can also be included in the $r$ -CD cavity (Figure 5).

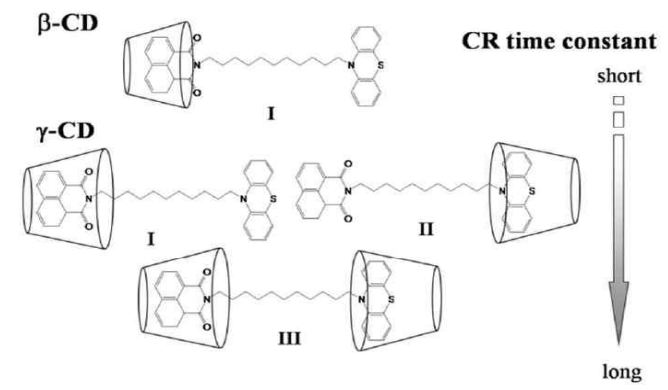

Figure 5. Possible structure of NI-PTZ dyad and CD. Reproduced from ref. 36 with permission of the PCCP Owner Societes. 
4.2 Electron transfer in donor-acceptor molecule linked by coordination bonding

Since majority of imide compounds exhibits good electron acceptor ability, combination of imides with porphyrinoids, which are often employed as model compounds of photosynthesis systems, has been investigated widely. Many research groups including Wasielewski et al. and Mataga et al. have investigated donor-acceptor dyad molecules using porphyrin and imides, in which imides are attached at meso- or $\beta$ -pyrrole of porphyrin rings. ${ }^{37-39}$ On the other hand, since Zn-coordinated porphyrin can take a pentacoordinated form by coordination of a ligand such as pyridine, introduction of an electron acceptor to the ligand facilitates formation of donor-acceptor dyads. ${ }^{40-41}$ The electron acceptor ligand can be applied to various tetra-pyrrole macrocycles such as porphyrins and phthalocyanines. As the electron acceptor ligand for $\mathrm{Zn}$ coordinated tetra-pyrrole macrocycles, we have synthesized PI, which possesses a pyridine ring for coordination at the $\mathrm{N}$ position of pyromellitimide (Figure 6). ${ }^{42}$

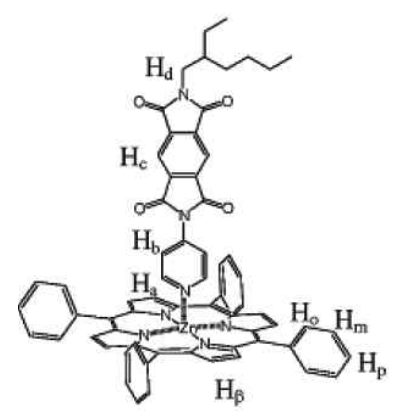

Figure 6. Structure of ZnTPP-PI complex. Reprinted with permission from ref. 42. Copyright (2007) American Chemical Society.

Coordination of PI to $\mathrm{Zn}$ coordinated tetra-pyrrole macrocycles was confirmed by UV-Vis absorption spectra and ${ }^{1} \mathrm{H}-\mathrm{NMR}$ measurements. For example, the absorption peaks (B- and Q-bands) of $\mathrm{Zn}$ tetraphenylporphyrin (ZnTPP) shifted to $429 \mathrm{~nm}$ and 562 and $601 \mathrm{~nm}$, respectively, which are the same as those of pyridine coordinated ZnTPP, indicating formation of the pentacoordinated form of ZnTPP with PI. By applying the Scatchard plot to the present absorption spectral change, the association constant was estimated to be $2400 \mathrm{M}^{-1}$. In addition, in the ${ }^{1}$ HNMR spectra, upon coordination of PI to ZnTPP lower field shift of hydrogen of pyridine ring of PI was observed supporting the coordination of pyridine $\mathrm{N}$ to the central $\mathrm{Zn}$ of ZnTPP. Similar supramolecular donor-acceptor dyad formation was confirmed with other $\mathrm{Zn}$ tetra-pyrrole macrocycles, $\mathrm{Zn}$ octaethylporphyrin (ZnOEP), Zn phthalocyanine (ZnPc), and $\mathrm{Zn}$ naphthalocyanine $(\mathrm{ZnNc})$. Molecular orbital (MO) calculation at B3LYP/6-31G(d) level indicated that the HOMO electron is localized on the macrocycles and LUMO is on pyromellitimide, while HOMO and LUMO electrons are not distributed on the pyridine ring, indicating that electron transfer from macrocycles in the singlet excited state to pyromellitimide is possible process and the pyridine ring acts as a spacer during the electron transfer process.

The charge separation process in the supramolecular dyads was confirmed by means of the sub-picosecond laser flash photolysis. In the experiment, excess amount (100 equiv.) of electron acceptor ligand was added to the solution of tetra-pyrrole macrocycles to ensure that the photoinduced process of the supramolecules can be elucidated. In the case of supramolecular dyad of ZnTPP and PI, transient absorption bands due to singlet excited ZnTPP was confirmed upon laser excitation. With decay of singlet excited ZnTPP, an absorption band of PI radical anion appeared, indicating the charge separation in the supramolecular dyad. The transient absorption bands due to charge separation were observed with other supramolecular dyads and the observed rate can be explained on the basis of the driving force for the electron transfer.

As indicated in above section, porphyrin derivatives have been used as a key pigment to develop various photofunctional and photoactive materials. For porphyrins, a series of isomers have been synthesized, namely porphycene, hemiporphycene, and corrphycene. ${ }^{43}$ These isomers have a large absorption in the red and near-IR regions because of their lower symmetry compared to porphyrins. Their redox properties can be controlled by selection of metal ion in the inner cavity like porphyrins. ${ }^{44}$ These points are attractive from the viewpoint of various applications. Compared to a number of studies on electron transfer process of porphyrin derivatives, examples of electron transfer of these porphyrin isomers are rather limited. In this section, we compared the electron transfer processes of the supramolecular dyads of ZnOEP, $2,3,6,7,12,13,16,17$-octaethylporphycenatozinc(II) (ZnPcn), 
octaethylhemiporphycenatozinc(II) (ZnHPc), and 2,3,6,7,11,12,17,18-octaethylcorrphycenatozinc(II)( $\mathrm{ZnCn})$, in which the latter three compounds are structural isomers of $\mathrm{ZnOEP}$ (Figure 7). ${ }^{45-47}$

For comparison purpose, we used a series of electron acceptor ligands, which are combination of phthalimide and pyridine ring (Figure 7). The $\mathrm{N}$ atom of pyridine ring can coordinate to the central $\mathrm{Zn}$ ion of these isomers like PI in the previous section.
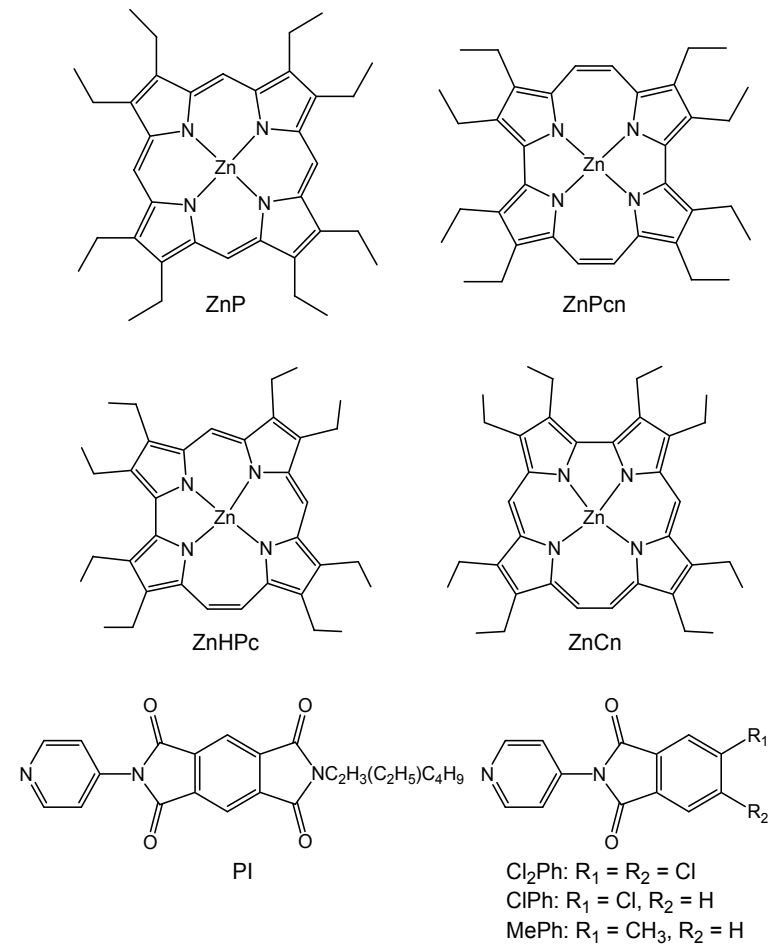

Figure 7. Molecular structures of ZnOEP, ZnHPc, $\mathrm{ZnPcn}, \mathrm{ZnCn} \mathrm{PI}$, and phthalimides $\left(\mathrm{Cl}_{2} \mathrm{Ph}, \mathrm{ClPh}\right.$, and $\mathrm{MePh}$ ). Reproduced from ref. 47 with permission of the PCCP Owner Societis.

Formation of the supramolecular dyad by coordination of the pyridine ring of the electron acceptor ligand to the central $\mathrm{Zn}$ ion was confirmed by absorption spectral change. The constant for the formation of pentacoordinated porphyrinoids was on the order of $10^{3}-10^{4} \mathrm{M}^{-1}$. Since the radical anion of phthalimide does not show obvious absorption peak in the visible region, observation of radical cation during the laser flash photolysis is essential to investigate electron transfer kinetics. Because there were no report on the absorption spectra of the radical cations of $\mathrm{ZnHPc}, \mathrm{ZnCn}$, and $\mathrm{ZnPcn}$, we measured their absorption spectra by means of $\Upsilon$-ray radiolysis of the sample in butylchloride rigid matrix at $77 \mathrm{~K}$, which is a well-established process in the field of radiation chemistry. $^{48}$ After the $\Upsilon$-ray irradiation, $\mathrm{ZnHPc}, \mathrm{ZnCn}$, and ZnPcn showed an absorption peak attributable to the corresponding radical cation at 756, 705, and 860 nm, respectively.

For each dyads, photoinduced charge separation was investigated using sub-picosecond laser flash photolysis employing the femtosecond laser pulse to excite the Q band of the supramolecular dyads, i. e. 565-, 610-, $560-$, and $650-\mathrm{nm}$ laser pulse for the $\mathrm{ZnOEP}, \mathrm{ZnHPc}$, $\mathrm{ZnCn}$, and $\mathrm{ZnPcn}$ supramolecular dyads, respectively. The generation of the charge separated state from the singlet excited state was confirmed by the observation of the transient absorption band of radical cation. It was revealed that the charge separation rate was in the order of $\mathrm{ZnOEP}>\mathrm{ZnHPc}, \mathrm{ZnCn}>\mathrm{ZnPcn}$ when the driving force was comparable. In Figure 8 , the estimated electron transfer rates were plotted against the driving force. ${ }^{47}$ Usually, the driving force dependence of electron transfer rate can be explained on the basis of the Marcus theory, eq. (1-3), ${ }^{49-50}$

$$
\begin{aligned}
k_{E T} & =\sqrt{\frac{\pi}{\hbar^{2} \lambda_{S} k_{B} T}}|V|^{2} \sum_{m}\left(e^{-S}\left(S^{m} / m !\right)\right) \exp \left(-\frac{\left(\lambda_{S}+\Delta G+m \hbar\langle\omega\rangle\right)^{2}}{4 \lambda_{S} k_{B} T}\right) \\
\lambda_{S} & =e^{2}\left(\frac{1}{2 r_{D}}+\frac{1}{2 r_{A}}-\frac{1}{r}\right)\left(\frac{1}{n^{2}}-\frac{1}{\varepsilon_{S}}\right) \\
. & \\
S & =\frac{\lambda_{V}}{\hbar\langle\omega\rangle}
\end{aligned}
$$

In eq (1), $\lambda_{\mathrm{S}}$ is the solvent reorganization energy given by eq. (2), $V$ is the electronic coupling, $S$ is the electron-vibration coupling constant given by eq. (3), and $\langle\omega\rangle$ is the averaged angular frequency. In eq. (2), $n$ is the refractive index. In eq. (3), $\lambda_{\mathrm{V}}$ is the internal reorganization energy. The $\lambda_{\mathrm{S}}$ value was estimated to be $0.05 \mathrm{eV}$. The estimated electron transfer rates can be reproduced by using the parameters listed in caption of Figure 8 . Thus, the $V$ value of the electron transfer of porphyrin isomers is in the order of $\mathrm{ZnOEP}>\mathrm{ZnHPc}>\mathrm{ZnCn}>\mathrm{ZnPcn}$, while the $\lambda_{\mathrm{V}}$ value is $\mathrm{ZnPcn}>\mathrm{ZnHPc}, \mathrm{ZnCn}>$ ZnOEP.

Figure 8. Free energy change $(-\triangle G)$ dependence of $\mathrm{ET}$ rate ( $k_{\mathrm{ET}}$, i.e., $k_{C S}$ (filled circle) and $k_{C R}$ (opened circle)) of ZnOEP (black), ZnPcn (blue), ZnHPc 


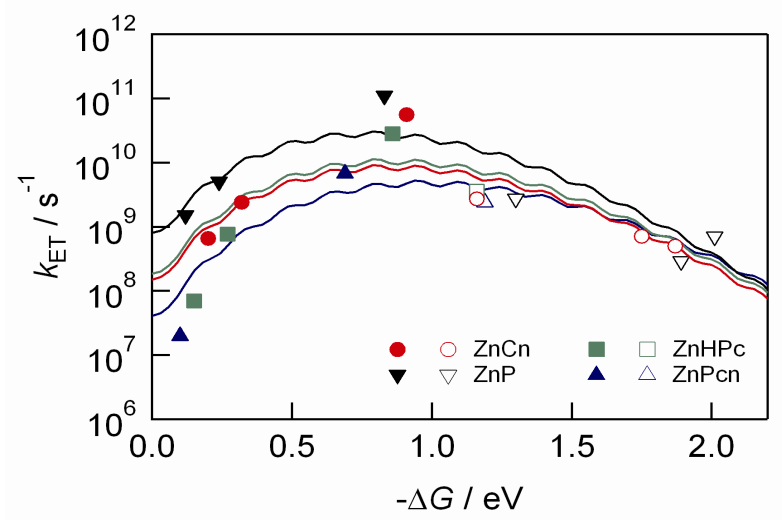

(green) and $\mathrm{ZnCn}$ (red) complexes. Black curve was calculated using eq. (1) in text by assuming $\lambda_{\mathrm{s}}=$ $0.050 \mathrm{eV}, V=0.0016 \mathrm{eV}, \hbar\langle\omega\rangle=0.15 \mathrm{eV}$, and $\lambda_{\mathrm{v}}$ $=0.80 \mathrm{eV}$ for porphyrins. Blue curve for $\mathrm{ZnPcn}$ was calculated by changing $V$ and $\lambda \mathrm{v}$ to 0.0007 and 1.0 $\mathrm{eV}$, respectively. For ZnHPc (green curve), the $V$ and $\lambda_{\mathrm{v}}$ values were 0.0010 and $0.9 \mathrm{eV}$, respectively. For $\mathrm{ZnCn}$ (red curve), the $V$ and $\lambda_{\mathrm{v}}$ values were 0.0009 and $0.9 \mathrm{eV}$, respectively. Reproduced from ref. 47 with permission of the PCCP Owner Societies.

For the detailed understanding of the observed tendency of electron transfer rates of the supramolecular dyads of $\mathrm{ZnOEP}, \mathrm{ZnHPc}, \mathrm{ZnCn}$, and $\mathrm{ZnPcn}, \mathrm{MO}$ and molecular structures were investigated by means of $\mathrm{MO}$ calculations, because these isomers have same MO pattern due to the same substitution pattern. $^{45-47}$ It has been pointed out that electron transfer rates from the excited porphyrinoids relate to HOMO electronic densities. ${ }^{37,}$ 51-52 The largest HOMO electron density was found at the a-carbon of pyrrole ring of each porphyrinoids of the present dyads. In the electronic coupling of donor and acceptor moieties for electron transfer, contribution of these carbons should be larger one. Distance between donor and acceptor is an important factor governing the electronic coupling. Because the same acceptor was employed in the calculation, the distance between $\mathrm{Zn}$ ion and the carbon with the largest HOMO electron density reflects the distance for the electronic coupling. The distance was estimated to be 3.10, 3.13, 3.16, and $3.19 \AA$ for $\mathrm{ZnOEP}, \mathrm{ZnHPc}, \mathrm{ZnCn}$, and $\mathrm{ZnPcn}$, respectively. This is the same order with that of the estimated $V$ value Thus, distribution of the HOMO electron density will give a plausible explanation for the variation in the $V$ values. Furthermore, as an origin of larger $\lambda_{\mathrm{V}}$ value of
$\mathrm{ZnPcn}, \mathrm{ZnCn}$, and $\mathrm{ZnHPc}$, larger structural change upon one electron oxidation was confirmed from MO calculation. ${ }^{47,53}$

4.3 Electron transfer between quantum dots and surface-attached imides

Photoinduced electron transfer to and from semiconductor quantum dots (QDs) is of intense interest because of its important roles in QD-based devices, such as detectors, light-emitting diodes, and solar cells. We investigated the solvent dependence of the interfacial electron transfer between ZnS-capped CdSe (CdSe/ZnS) QDs and PI at the ensemble and single-particle levels. ${ }^{54}$ The steady-state and time-resolved photoluminescence and absorption measurements revealed that the rates of electron transfer from the excited $\mathrm{CdSe} / \mathrm{ZnS}$ to the adsorbed PI molecules in non-polar solvents, such as octane and toluene, are higher than aprotic polar solvents, such as benzonitrile. Furthermore, it was found that two pathways were included in the electron transfer processes between $\mathrm{CdSe} / \mathrm{ZnS}$ and $\mathrm{PI}$, that is, electron transfer from the excited CdSe core to PI molecules adsorbed on the surface of the CdSe or $\mathrm{ZnS}$. The former process occurred on the picosecond timescale, while the latter was on the nanosecond time scale. The interfacial electron transfer dynamics in individual $\mathrm{CdSe} / \mathrm{ZnS}-\mathrm{PI}$ conjugates in different solvents were also examined. The photoluminescence intermittency or blinking kinetics of single QDs was analyzed by adapting a diffusion-controlled electron transfer theory for the probability distribution of the "on" events. The results, which are qualitatively consistent with that obtained from the bulk experiments, clearly showed that the probability of the electron transfer events increases with the decreasing solvent polarity.

4.4 Application to DNA sequence detection on the basis of charge transfer in DNA

Oxidation and reduction reactions of DNA are essential in various biological processes in DNA. Because charge transfer in DNA explains oxidation and reduction of nucleobase apart from the initially oxidized and reduced site, respectively, charge transfer in DNA attracts attentions of researchers in wide fields including biology and nanotechnology. Imide compounds are often employed as a photosensitizing electron acceptor, i.e. hole injector, in studies on hole transfer in DNA. ${ }^{32}$ Because hole transfer efficiency largely depends on DNA sequence, a detection method of DNA sequence will be possible on the basis of the 
charge transfer efficiency. Photocurrent measurement will be one of the candidates for this purpose. ${ }^{55} \mathrm{We}$ applied the single molecular fluorescence detection to DNA sequence analysis. ${ }^{56-57}$

In the experiments, DNA was conjugated with the photosensitizing electron acceptor (NI) and reporter fluorescent molecule $(\mathrm{Fl})$ at the both ends (Figure 9). ${ }^{56}$ Transfer of an injected hole to Fl quenched the fluorescence, while mismatch in DNA deceased the amount of fluorescence quenching by diminishing the hole transfer in DNA. It is clear from bottom of Figure 9 that the photobleaching efficiency decreased when the DNA included the mismatch. It was revealed that the efficiency was sensitive to the position of mismatch.
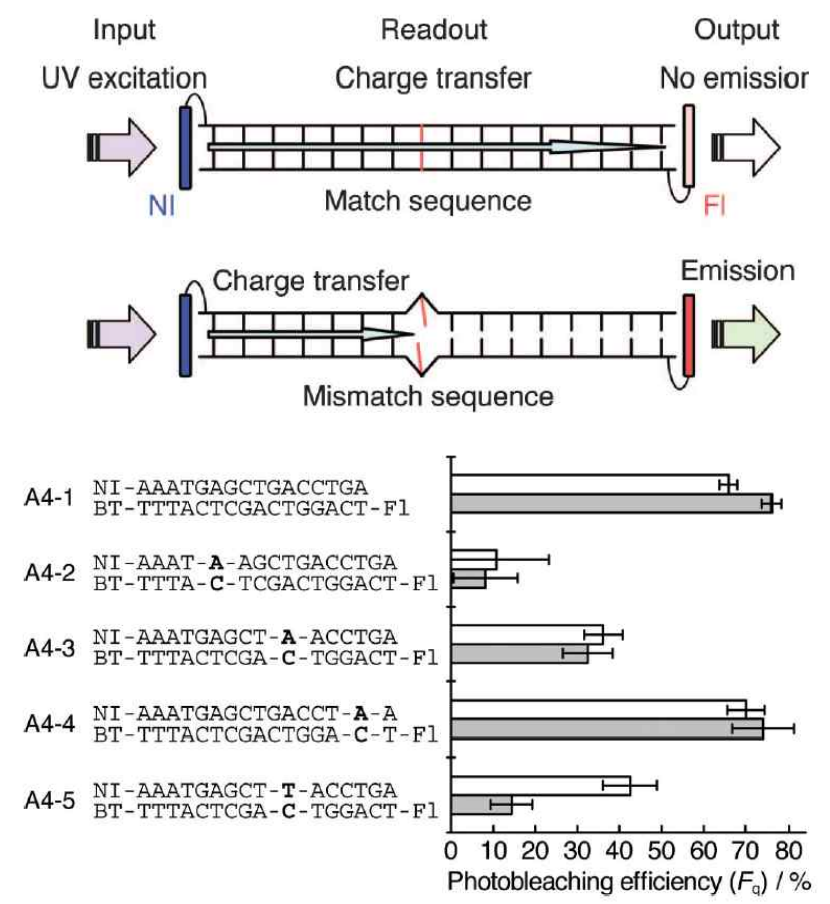

Figure 9. Bleaching of the fluorescence from the reporter molecule due to the hole migration and the inhibition by mismatch sequence. Reproduced from ref. 56. Copyright (2007) National Academy of Sciences, U.S.A

In above DNA system, combination of NI and Fl realized DNA mismatch detection system, in which charge transfer diminished fluorescence intensity. In order to realize DNA, in which charge transfer enhances fluorescence intensity, we examined another DNA system, that is, Black Hole Quencher (BHQ) was placed inside DNA while NI and Fl were located at both ends. In this DNA, Fl and BHQ were located at close position so that fluorescence from $\mathrm{Fl}$ was quenched by FRET. On the other hand, transfer of injected hole to BHQ cancels FRET resulting fluorescence from Fl. This fluorescence "ON" upon charge transfer was successfully observed with single molecular fluorescence method. The sensitivity to the mismatch sequence was also confirmed. ${ }^{57}$

In this section, we introduced various electron transfer systems using imides as electron acceptor. In spite of differences in the linking method and donor part, imides showed suitable electron acceptor ability in each case. Furthermore, molecular structure which enables various bonding method and characteristic absorption band upon one-electron reduction are favorite properties for many chemists who are engaged to synthetic and spectroscopic studies. Tendency of imides to form various kinds of aggregates is important characteristic. Based on this characteristic, electron migration phenomena of nano-structured imides will be also clarified to utilize in the charge relay systems. From these points, imides compounds will be utilized in various electron transfer systems also in future.

\section{Higher excited state and multi-laser chemistries}

Photoinduced reaction usually occurs from the lowest excited state such as the lowest singlet and the lowest triplet excited states. This comes from the ultrafast internal conversion from the higher excited states to the lowest excited state in solution phase. Therefore, in usual photochemistry, excitation wavelength dependence cannot be observed as known as Kasha's rule. However, since the internal conversion rate in solution is on the order of picoseconds, if the reaction is fast enough, photoinduced reaction from the higher excited state is also possible. Recent development of various experimental methods for the investigation of the ultrafast phenomena also makes the observation of the reaction via higher excited state possible. Our research group has been engaged to the study of the higher excited state chemistry for years. ${ }^{58}$ Our research interests cover the reactions from the higher singlet state, higher triplet state, excited radical, i.e. excited doublet state, and so on. Furthermore, application of the multi-laser irradiation technique, which realizes the excitation chemistry of short-lived reaction intermediates, enlarges the field of excitation chemistry. We found that imide compounds are also useful to these studies. In this section, application of the imide compounds to such study is overviewed. 


\subsection{Electron transfer from the higher excited state}

Higher excited states can be generated by various ways. In the case of the higher singlet excited state, excitation of the absorption band corresponding to the $\mathrm{S}_{\mathrm{n}} \leftarrow \mathrm{S}_{0}(\mathrm{n} \geq 2)$ generates higher singlet state, while in the case of the higher triplet state two-color two-laser excitation is usually needed for the efficient higher triplet excited-state generation. Thus, the higher singlet state can be accessed rather easily. For example, ZnTPP exhibits a strong absorption band at $423 \mathrm{~nm}$ called as Soret or B-band, which corresponds to the absorption band to generate higher excited state upon excitation, while Q-bands at $550-$ and $587 \mathrm{~nm}$ correspond to the absorption bands to generate the lowest excited state. When the Soret-band of ZnTPP is excited, ZnTPP shows $\mathrm{S}_{2}$-fluorescence, of which lifetime was determined to be $\sim 3$ ps. Chosrowjan et al. found that the $\mathrm{S}_{2}$-fluorescence lifetime of $\mathrm{ZnTPP}$ in $\mathrm{CH}_{2} \mathrm{Cl}_{2}$ was $0.75 \mathrm{ps}$, indicating the electron transfer from $\mathrm{ZnTPP}$ in the $\mathrm{S}_{2}$-excited state to solvent, which was confirmed by transient absorption spectroscopy. ${ }^{59}$ Thus, shorter distance between ZnTPP and acceptor, i. e. solvent molecule, enhances the electron transfer rate which can compete with the internal conversion. Following to this result, electron transfer between ZnTPP in the $\mathrm{S}_{2}$-excited state and covalently bonded acceptor was reported by various research groups, such as Hammarström et al., Wasielewski et al., and Mataga et al. ${ }^{37-39,} 60$ Especially, the research group of Mataga revealed driving force dependence of the electron transfer rate from the $\mathrm{S}_{2}$-excited state. ${ }^{38-39}$ Our research group also reported electron transfer from SbTPP and PTPP in the $\mathrm{S}_{2}$-excited state, in which TPPs act as electron acceptors. ${ }^{61-62}$ These results successfully revealed the characteristics of the $\mathrm{S}_{2}$ electron transfer which is different from the $\mathrm{S}_{1}$ electron transfers.

The $\mathrm{S}_{2}$ electron transfer was also investigated with the supramolecular donor-acceptor dyad systems using imide compounds, ${ }^{42}$ which were indicated in the previous section, i.e., ZnTPP, $\mathrm{ZnOEP}, \mathrm{ZnPc}$, and $\mathrm{ZnNc}$ as an electron donor while PI as an electron acceptor. Generation of the $\mathrm{S}_{2}$-excited state can be achieved by using 400-nm laser pulse, which excites the Soret band. In the case of ZnTPP-PI, generation of charge separated state was confirmed with the appearance of radical anion of PI with the apparent rate of $5.6 \times$ $10^{11} \mathrm{~s}^{-1}$, which is much faster than that obtained by excitation of Q-band, i. e., the S1-excited state, indicating that the electron transfer occurred from the
$\mathrm{S}_{2}$-excited state. When the deactivation rate of the pristine $\mathrm{ZnTPP}$ in the $\mathrm{S}_{2}$-excited state taking into account, the electron transfer rate and quantum yield from the $\mathrm{S}_{2}$-excited state were calculated to be $2.1 \times$ $10^{11} \mathrm{~s}^{-1}$ and 0.63 , respectively. The lower yield than that of the $S_{1}$ electron transfer can be explained based on the rapid internal conversion from the $S_{2-}$ to $\mathrm{S}_{1}$-excited state. The lifetime of the charge separated state was $650 \mathrm{ps,}$ which was the same as that from the $\mathrm{S}_{1}$-excited state, indicating that the difference in the original states, $\mathrm{S}_{2^{-}}$or $\mathrm{S}_{1}$-excited state, does not give the difference in the charge separated state, which deactivates to the neutral ground state by charge recombination process. Similarly, electron transfer from the $\mathrm{S}_{2}$-excited state was confirmed with the supramolecular donor-acceptor dyad of $\mathrm{ZnPc}$ and PI. The rate and yield were estimated to be $3.5 \times$ $10^{10} \mathrm{~s}^{-1}$ and 0.33 , respectively. On the other hand, the generation rate of the charge separated state did not show wavelength dependence in the cases of $\mathrm{ZnNc}-\mathrm{PI}$ and $\mathrm{ZnOEP-PI}$ dyads, indicating that the electron transfer did not occur from the $\mathrm{S}_{2}$-excited state. In the case of $\mathrm{ZnOEP}$, quite short $\mathrm{S}_{2}$-excited state lifetime was reported, which decreases the yield of electron transfer from the $\mathrm{S}_{2}$-excited state. On the other hand, smaller driving force for the $\mathrm{ZnNc}$-PI seems to make the $\mathrm{S}_{2}$ electron transfer inefficient.

Since the reorganization energy for the electron transfer of these dyads are $0.5-1.0 \mathrm{eV}$, the electron transfer from $\mathrm{S}_{1}$-excited $\mathrm{ZnTPP}$ or ZnOEP to the axial ligand will exhibit rate close to maximal one. In the case of $\mathrm{S}_{2}$ electron transfer, the driving force should be larger than that of the $S_{1}$ electron transfer by the energy difference between the $\mathrm{S}_{2}$ - and $\mathrm{S}_{1}$-excited states, suggesting that the electron transfer from the $\mathrm{S}_{2}$-excited state is located in the inverted region decelerating the electron transfer rate. However, as indicated above, electron transfer from the $\mathrm{S}_{2}$-excited state was faster than that of $\mathrm{S}_{1}$-excited state. This fact indicates that the electron transfer from the $\mathrm{S}_{1-}$ and $\mathrm{S}_{2}$-excited states cannot be explained by the same Marcus parabola. There are two possibilities which can explain this observation: One possibility is that electron transfer from the $\mathrm{S}_{2}$-excited state generates the excited radical ion pair state, which diminishes the driving force. Another possibility is that the $\mathrm{S}_{2}$ electron transfer obeys different Marcus parabola from that of the $\mathrm{S}_{1}$-excited state due to difference in the reorganization energy. Further detailed study is needed to understand which model is reasonable to describe 
electron transfer from the higher excited state.

\subsection{Energy transfer from the higher excited state}

As indicated above, by using multi-laser excitation technique such as two-color two-laser excitation, one can access to various excited states including the higher triplet and excited radicals. In the two-color two-laser excitation, two laser pulses with controlled wavelength and delay are irradiated to the sample. For the higher triplet excited-state generation, the first pulse is irradiated to the sample to generate the lowest triplet state via the intersystem crossing, while the second laser, of which wavelength is tuned to be absorbed by the lowest triplet state, is irradiated within the lifetime of the triplet excited state. Two points are emphasized as characteristics of this method. One is that because of the higher energy of the higher excited state various reactions become possible even when these reactions are impossible from the lowest excited state. Another point is that these reactions become site and time-selective. Site selectivity indicates that the reaction is only possible at the cross point of two lasers. Time selectivity indicates that the reaction is possible within the lifetime of the reaction intermediate generated by the first laser, i.e. the yield and product selectivity can be controlled by the interval of two lasers. We have applied this multi laser irradiation to generate various intermediates and revealed reactions possible only from the higher excited state, including electron and energy transfers, bond cleavage and so on. The site-selectivity is useful to fabricate materials in a confined volume. Actually, we applied this method to generate metal nano-particles such as gold and copper in a limited volume. One of utilizations of time-selectivity of multi-laser irradiation in molecular devices should be product control by two laser excitation. Here, we introduce our results on the molecular systems, of which product, in the excited state in this case, can be controlled by the laser excitation.

In Figure 10, molecular structure of the examined molecule and schematic energy diagram are indicated. $^{63}$ This molecule is a triad molecule including pyrene (Py), biphenyl $\left(\mathrm{Ph}_{2}\right)$, and bisimidethiophene (ImT). In this molecular array, the $\mathrm{S} 1$ energy of $\operatorname{ImT}$ is the lowest, thus $\mathrm{S}_{1}$-excited state of ImT should be generated by energy transfer even when $\mathrm{Py}$ or $\mathrm{Ph}_{2}$ is excited. The intersystem crossing generates the $T_{1}$ state of $\operatorname{ImT}$ (State 1), which is to be excited by the second laser to generate the $T_{n}$ (n $\geq 2$ ) state of $\operatorname{ImT}$. The energy transfer from $T_{n}$ ( $n$ $\geq 2$ ) generates $P y$ in the $T_{1}$ state (State 2). Thus, the second laser acts as a switch of the products, i. e., State 1 or 2 .

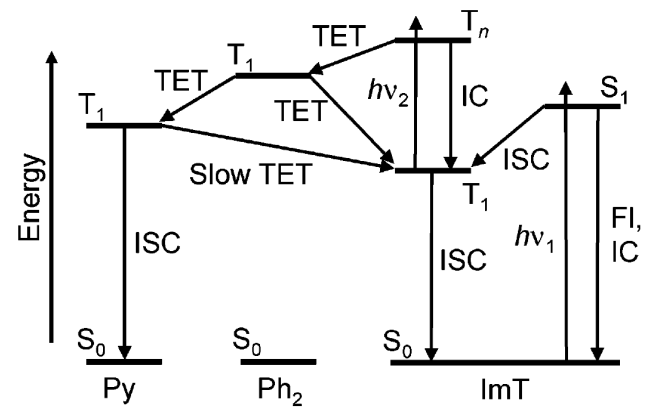

Figure 10. Molecular structure of $\left(\mathrm{Py}^{-} \mathrm{Ph}_{2}\right)_{2} \operatorname{ImT}$ and energy diagram during the two-color two-laser photolysis. Reproduced from ref. 63. Copyright (2007) American Chemical Society

When the 355-nm laser was irradiated to the triad molecule as the first laser, transient absorption band of $\mathrm{T}_{1}$ state of $\operatorname{ImT}$ was observed at $650 \mathrm{~nm}$. Although Py also absorbs light at $355 \mathrm{~nm}$, energy transfer generates $\operatorname{ImT}\left(\mathrm{T}_{1}\right)$ state. The 532-nm laser as the second laser is absorbed selectively by $\operatorname{ImT}\left(\mathrm{T}_{1}\right)$ generating $\operatorname{ImT}\left(T_{n}\right)$. In the transient absorption spectrum, absorption band of $\operatorname{ImT}\left(\mathrm{T}_{1}\right)$ decreased and a transient absorption peak appeared at $415 \mathrm{~nm}$ due to $\operatorname{Py}\left(\mathrm{T}_{1}\right)$, indicating the energy transfer from $\operatorname{ImT}\left(\mathrm{T}_{n}\right)$. The present energy transfer from $\operatorname{ImT}\left(\mathrm{T}_{\mathrm{n}}\right)$ is a stepwise process including the generation of $\mathrm{Ph}_{2}\left(\mathrm{~T}_{1}\right)$, because $\mathrm{Py}\left(\mathrm{T}_{1}\right)$ did not appear when $\mathrm{Ph}_{2}$ is changed to a phenyl ring. Although energy transfer from $\mathrm{Ph}_{2}$ to $\operatorname{ImT}$ is also possible process, energy transfer generates $\operatorname{Py}\left(\mathrm{T}_{1}\right)$ only. The lifetime of $\mathrm{Py}\left(\mathrm{T}_{1}\right)$ (State 2) ranged to several tens microsecods, and finally deactivates to $\operatorname{Im}\left(T_{1}\right)$ by slow energy transfer. This result indicates that the second laser irradiation control the generation of $\mathrm{Py}\left(\mathrm{T}_{1}\right)$ as a molecular switch.

\subsection{Electron transfer caused by multi-laser excitation}

Cyclic reactions enable efficient chemical reactions from limited reagents and energies. In nature, organisms have developed a variety of cyclic reactions including photocatalytic and enzymatic systems. From the viewpoint of efficient application of light energy, 
artificial catalytic cycles have attracted attentions. We designed a new cyclic reaction based on the concept of two-color two-laser excitation (Figure 11). ${ }^{64}$ For this purpose, N-methylphthalimide (MePh)-linked 4-methoxybenzophenone (MeOBP) was synthesized. The excited benzophenone ketyl radical formed by the two-color two-laser excitation reduces the $\mathrm{MePh}$ moiety to form the diphenylmethanol cation and the $\mathrm{MePh}$ radical anion $\left(\mathrm{MePh}^{\circ}\right)$. The cation quickly deprotonates to regenerate MeOBP. In the presence of an appropriate electron acceptor, $\mathrm{MePh}^{\circ}$ reduces the acceptors to regenerate the initial state. As a result, the cyclic reaction is completed. The proposed cyclic reaction produces one reducing reagent (radical anion) and one proton from two photons (UV and visible light) and a hydrogen donor.

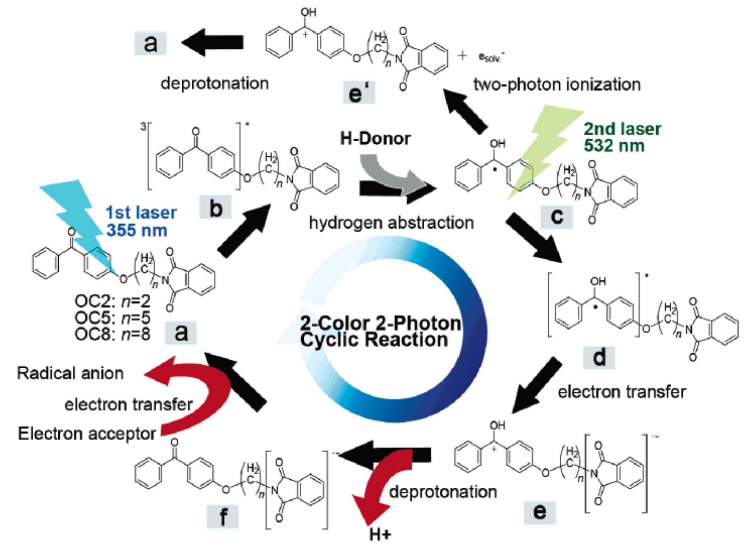

Figure 11. Cyclic reaction based on the concept of the two-color two-laser excitation using $\mathrm{N}$-methylphthalimide (MePh)-linked 4-methoxybenzophenone (MeOBP). Reproduced from ref. 64. Copyright (2007) American Chemical Society.

\subsection{Application of multi-laser excitation to DNA cleavage}

Photodynamic therapy (PDT) is a promising treatment of cancer based on the photosensitized oxidative reaction at the diseased tissues producing cell death, and DNA is considered as a potential target. ${ }^{65}$ Compared with surgery and chemotherapy, the combination of a photosensitizer (S) uptake in malignant tissues and selective light delivery offers the advantage of a selective method of destroying diseased tissues without damaging surrounding healthy tissues. Excitation of DNA-bound sensitizers produces the $\mathrm{S}^{\bullet-}$ / $\mathrm{DNA}^{\cdot+}$ charge-separated state through photoinduced electron transfer. However, the efficiency of producing photosensitized DNA damage is low because the charge recombination rate is usually much faster than the process leading to DNA damage, such as the reaction of $\mathrm{G}^{\cdot+}$ with water. Here, we introduce the first study of the nanosecond-laser DNA damaging, using a combination of two-color two-laser pulses as a promising new strategy to reach a high DNA damaging efficiency. ${ }^{66}$ The first laser pulse was applied for the production of $\mathrm{S}^{\cdot-}$ and $\mathrm{DNA}^{\cdot+}$, and the second laser pulse for the electron ejection from $\mathrm{S}^{*}$, making the reaction irreversible (Figure 12).

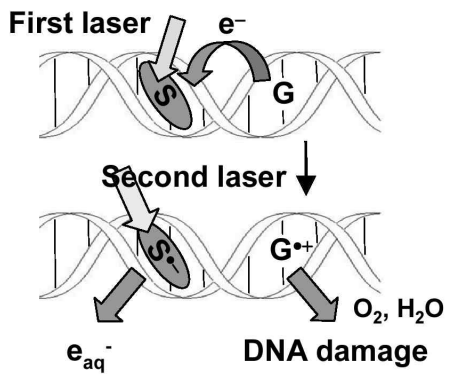

First laser $355 \mathrm{~nm}$

Excitation of $\mathrm{S}$

Electron transfer

Second laser $532 \mathrm{~nm}$

Excitation of $\mathrm{S}^{-}$

Electron ejection

Figure 12. Two-color two-laser approach to induce DNA damage. The first laser pulse was applied for the production of $\mathrm{S}^{-}$and $\mathrm{DNA}^{-+}$, and the second laser pulse for the electron ejection from $\mathrm{S}^{\bullet}$, making the reaction irreversible. Reproduced from ref. 66 . Copyright 2004 WILEY-VCH Verlag GmbH \& Co. KGaA, Weinheim.

In this study, naphthaldiimide (NDI) was selected as an $\mathrm{S}$ that can be excited with a first laser at a wavelength of $355 \mathrm{~nm}$. First, to assess the feasibility of electron ejection from $\mathrm{S}^{\circ}$ bound to DNA, the pulse radiolysis-laser flash photolysis of NDI-conjugated oligodeoxynucleotide (NDI-ODN) was performed. NDI $^{-}$with a maximum absorption peak at $495 \mathrm{~nm}$ was generated from the electron attachment during the pulse radiolysis of NDI-ODN. Since $\mathrm{S}^{-}$often absorbs light at a longer wavelength compared with its non-reduced form, laser pulses with a longer wavelength can be used for the excitation of $\mathrm{S}^{\circ}$, and a 532-nm laser was applied as the second laser. Irradiation of $\mathrm{NDI}^{\circ-}$ in NDI-ODN with a 532-nm laser pulse caused a decrease in $\triangle$ O.D. of $\mathrm{NDI}^{\circ}$, and the formation of absorption at $630 \mathrm{~nm}$ assigned to a solvated electron $\left(\mathrm{e}_{\mathrm{aq}}{ }^{-}\right)$immediately after the laser pulse, demonstrating the successful electron ejection from $\mathrm{NDI}^{*}$ to the solvent water.

Figure 13 shows the time profile of $\mathrm{NDI}^{-}$in the 
one-color laser photolysis of NDI-ODN. Upon the first laser excitation, hole transfer via consecutive fast adenine hopping leads to a charge-separated state within the laser duration (5 ns), and the charge recombination proceeds by the single-step super exchange from guanine $(G)$ radical cation $\left(\mathrm{G}^{\cdot+}\right)$ about $14 \AA$ away from $\mathrm{NDI}^{\circ}$ with a lifetime of $240 \mathrm{~ns}$. Figure 13 also shows the consumption of $G$ as a function of the delay time of the second laser pulse in the two-color photolysis. The delay time dependence of the consumption of $\mathrm{G}$ agreed well with the decay of the transient absorption of $\mathrm{NDI}^{-}$ obtained in the one-color laser photolysis. Thus, the acceleration caused by the second laser is clearly based on the excitation of $\mathrm{NDI}^{*}$. The experiments were performed under single-hit (i.e., low-conversion) conditions where, on average, each duplex reacts once or not at all, and the consumption of $G$ was linearly correlated with the irradiation time and the power of the second laser in the present experimental arrangement.

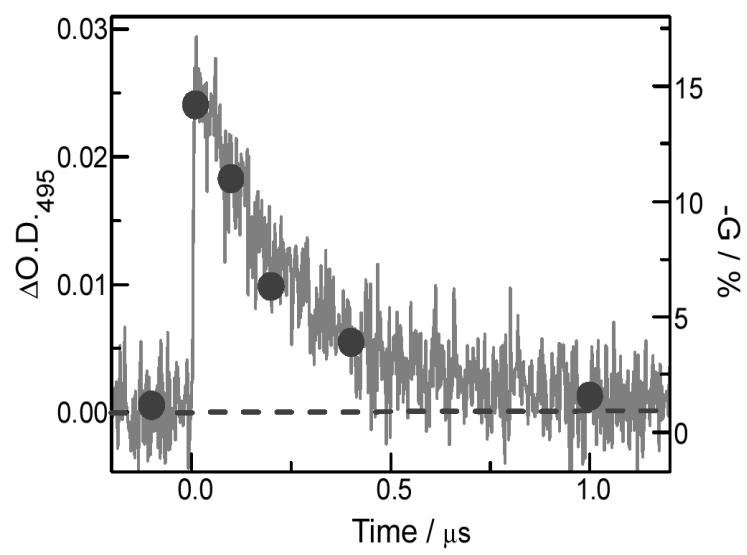

Figure 13. Formation and decay of $\mathrm{NDI}^{--}$and the effect of the delay time between two laser pulses on the consumption of $\mathrm{G}$ during the laser flash photolysis of NDI-ODN (NDI-TTTCGCGCTT/AAAGCGCGAA). The transient absorption of $\mathrm{NDI}^{-}{ }^{-}$was monitored at $495 \mathrm{~nm}$ following the $355-\mathrm{nm}$ excitation (left axis). The consumption of $\mathrm{G}$ is plotted as a function of the delay of the 532-nm pulse with respect to the 355-nm pulse $(\bullet$, right axis). The dashed line shows the consumption of $\mathrm{G}$ in the absence of the 532-nm pulse. Reproduced from ref. 66. Copyright 2004 WILEY-VCH Verlag GmbH \& Co. KGaA, Weinheim In the present section, we summarized higher excited state chemistry and chemistry induced by multi-laser excitation. Although, the examples of this chemistry are limited, by employing the recent advanced spectroscopic methods, various important features of these chemistries became clearer. Sharp and strong absorption band of one-electron reduced imides are good target to study these issues. For example, in the higher excited state chemistry, these spectral features are favorable to detect a reaction even when the yield is low. And in the multi laser excitation, sharp and strong absorption facilitates excitation using second or third lasers. Imides itself will be the target of these study, such study is under progress.

\section{Conclusions}

In the present review, we introduced various photoinduced processes of supramolecular systems using imides mainly. Because of high electron acceptor ability in the excited state and excellent fluorescence properties of imides, imides are recognized as excellent components for various photofunctional molecular devices. In addition, rigid structure and higher stability under photoirradiation increased its applicability to various fields including biological fields. As indicated in this review, in spite of a number of studies, still various properties such as excited radical anion and higher excited states of these compounds are unknown. Taking their spectroscopic and redox properties into account, these compounds are good candidates such studies. Although we indicated some future perspectives in the summary of each parts of this review, further progresses in the fundamental and application science will be attained using these compounds in the various scientific fields.

KEYWORDS: Laser flash photolysis, Transient absorption, Single molecule spectroscopy, Porphyrin, $\mathrm{TiO}_{2}$, DNA, Higher excited state

Received January 14, 2014; Accepted February 14, 2014

\section{ACKNOWLEDGEMENT}

We are grateful to a number of collaborators, especially Prof. Dae Won Cho, Korea University, and Prof. Kiyohiko Kawai, Prof. Takashi Tachikawa, and Prof. Akira Sugimoto, Osaka University. This work has been partly supported by a Grant-in-Aid for Scientific Research (Project 25220806, 25288035, and others) from the Ministry of Education, Culture, 
Sports, Science and Technology (MEXT) of Japanese Government.

\section{REFERENCES}

1. Fujitsuka, M.; Majima, T., Photoinduced electron transfer processes in biological and artificial supramolecules. In Supramolecular Chemistry: From Molecules to Nanomaterials, Gale, P. A.; Steed, J. W., Eds. John Wiley \& Sons Ltd.: 2012; Vol. 5, pp 2365-2395.

2. Wasielewski, M. R., Chem. Rev. 1992, 92 (3), 435-61.

3. Kavarnos, G. J.; Turro, N. J., Chem. Rev. 1986, $86,401-449$

4. Fujitsuka, M.; Ito, O., Photochemistry of fullerenes. In Handbook of Photochemistry and Photobiology, Nalwa, H. S., Ed. American Scientific Publishers: California, 2003; Vol. 2, pp 111-145.

5. Wasielewski, M. R., J. Org. Chem. 2006, 71 (14), 5051-5066.

6. Heek, T.; Fasting, C.; Rest, C.; Zhang, X.; Wurthner, F.; Haag, R., Chem Commun 2010, 46 (11), 1884-6.

7. Gosztola, D.; Niemczyk, M. P.; Svec, W.; Lukas, A. S.; Wasielewski, M. R., J. Phys. Chem. A 2000, 104 (28), 6545-6551.

8. Wuerthner, F., Pure Appl. Chem. 2006, 78 (12), 2341-2349.

9. Greenfield, S. R.; Svec, W. A.; Gosztola, D.; Wasielewski, M. R., J. Am. Chem. Soc. 1996, 118 (28), 6767-6777.

10. Zhao, Y.; Wasielewski, M. R., Tetrahedron Lett. 1999, 40 (39), 7047-7050.

11. Liu, Y.; Yang, C.; Li, Y.; Li, Y.; Wang, S.; Zhuang, J.; Liu, H.; Wang, N.; He, X.; Li, Y.; Zhu, D., Macromolecules 2005, 38 (3), 716-721.

12. Mikroyannidis, J. A.; Stylianakis, M. M.; Sharma, G. D.; Balraju, P.; Roy, M. S., J. Phys. Chem. C 2009, 113 (18), 7904-7912.

13. Ford, W. E.; Kamat, P. V., J. Phys. Chem. 1987, 91 (25), 6373-80.

14. Holtrup, F. O.; Muller, G. R. J.; Quante, H.; De Feyter, S.; De Schryver, F. C.; Mullen, K., Chem. --Eur. J. 1997, 3 (2), 219-225.

15. Wintgens, V.; Valet, P.; Kossanyi, J.; Biczok, L.; Demeter, A.; Berces, T., J. Chem. Soc., Faraday Trans. 1994, 90, 411.

16. Osuka, A.; Nakajima, S.; Maruyama, K.; Mataga, N.; Asahi, T.; Yamazaki, I.; Nishimura, Y.; Ohno, T.; Nozaki, K., J. Am. Chem. Soc. 1993, 115 (11), 4577-89.

17. Wiederrecht, G. P.; Niemczyk, M. P.; Svec, W. A.; Wasielewski, M. R., J. Am. Chem. Soc. 1996,
118 (1), 81-8.

18. Baumstark, D.; Wagenknecht, H.-A., Angew. Chem., Int. Ed. 2008, 47 (14), 2612-2614.

19. Görl, D.; Zhang, X.; Würthner, F., Angew. Chem. Int. Ed. 2012, 51 (26), 6328-6348.

20. Giaimo, J. M.; Lockard, J. V.; Sinks, L. E.; Scott, A. M.; Wilson, T. M.; Wasielewski, M. R., J. Phys. Chem. A 2008, 112 (11), 2322-2330.

21. Yagai, S.; Seki, T.; Karatsu, T.; Kitamura, A.; Wurthner, F., Angew. Chem., Int. Ed. 2008, 47 (18), 3367-3371.

22. Hirayama, F., J. Chem. Phys. 1965, 42, 3163.

23. Cho, D. W.; Fujitsuka, M.; Sugimoto, A.; Majima, T., J. Phys. Chem. A 2008, 112 (31), 7208-7213.

24. Cho, D. W.; Fujitsuka, M.; Choi, K. H.; Park, M. J.; Yoon, U. C.; Majima, T., J. Phys. Chem. B 2006, 110 (10), 4576-4582.

25. Cho, D. W.; Fujitsuka, M.; Yoon, U. C.; Majima, T., J. Photochem. Photobiol. A, Chem. 2007, 190 (1), 101-109.

26. Tatsuma, T.; Tachibana, S.-i.; Miwa, T.; Tryk, D. A.; Fujishima, A., J. Phys. Chem. B 1999, 103 (38), 8033-8035.

27. Naito, K.; Tachikawa, T.; Cui, S.-C.; Sugimoto, A.; Fujitsuka, M.; Majima, T., J. Am. Chem. Soc. 2006, 128 (51), 16430-16431.

28. Wuerthner, F., Chem. Commun. 2004, (14), 1564-1579.

29. Wasielewski, M. R., Acc. Chem. Res. 2009, 42 (12), 1910-1921.

30. Frischmann, P. D.; Mahata, K.; Wurthner, F., Chem. Soc. Rev. 2013, 42 (4), 1847-1870.

31. Takada, T.; Kawai, K.; Fujitsuka, M.; Majima, T., Proc. Natl. Acad. Sci. U. S. A. 2004, 101 (39), 14002-14006.

32. Fujitsuka, M.; Majima, T., Phys. Chem. Chem. Phys. 2012, 14 (32), 11234-11244.

33. Fujitsuka, M.; Harada, K.; Sugimoto, A.; Majima, T., J. Phys. Chem. A 2008, 112 (41), 10193-10199.

34. Cho, D. W.; Fujitsuka, M.; Sugimoto, A.; Yoon, U. C.; Mariano, P. S.; Majima, T., J. Phys. Chem. B 2006, 110 (23), 11062-11068.

35. Cho, D. W.; Fujitsuka, M.; Yoon, U. C.; Majima, T., Phys. Chem. Chem. Phys. 2008, 10 (30), 4393-4399.

36. Cho, D. W.; Fujitsuka, M.; Sugimoto, A.; Yoon, U. C.; Cho, D. W.; Majima, T., Phys. Chem. Chem. Phys. 2014, in press.

37. Hayes, R. T.; Walsh, C. J.; Wasielewski, M. R., J. Phys. Chem. A 2004, 108 (13), 2375-2381.

38. Mataga, N.; Chosrowjan, H.; Shibata, Y.; Yoshida, N.; Osuka, A.; Kikuzawa, T.; Okada, T., J. Am. Chem. Soc. 2001, 123 (49), 12422-12423. 
39. Mataga, N.; Chosrowjan, H.; Taniguchi, S.;

Shibata, Y.; Yoshida, N.; Osuka, A.; Kikuzawa, T.; Okada, T., J. Phys. Chem. A 2002, 106 (51), 12191-12201.

40. Anderson, H. L.; Hunter, C. A.; Sanders, J. K. M., J. Chem. Soc., Chem. Commun. 1989, 226-227.

41. Otsuki, J.; Takatsuki, M.; Kaneko, M.; Miwa, H.; Takido, T.; Seno, M.; Okamoto, K.; Imahori, H.; Fujitsuka, M.; Araki, Y.; Ito, O.; Fukuzumi, S., J. Phys. Chem. A 2003, 107 (3), 379-385.

42. Harada, K.; Fujitsuka, M.; Sugimoto, A.; Majima, T., J. Phys. Chem. A 2007, 111 (45), 11430-11436.

43. Fowler, C. J.; Sessler, J. L.; Lynch, V. M.; Waluk, J.; Gebauer, A.; Lex, J.; Heger, A.; Zuniga-y-Rivero, F.; Vogel, E., Chem. --Eur. J. 2002, 8 (15), 3485-3496.

44. Bernard, C.; Gisselbrecht, J. P.; Gross, M.; Vogel, E.; Lausmann, M., Inorg. Chem. 1994, 1994 (33), 2393-2401.

45. Fujitsuka, M.; Shimakoshi, H.; Tojo, S.; Cheng, L.; Maeda, D.; Hisaeda, Y.; Majima, T., J. Phys. Chem. A 2009, 113 (14), 3330-3335.

46. Fujitsuka, M.; Shimakoshi, H.; Tojo, S.; Cheng, L.; Maeda, D.; Hisaeda, Y.; Majima, T., J. Phys. Chem. A 2010, 114 (12), 4156-4162.

47. Fujitsuka, M.; Shimakoshi, H.; Tei, Y.; Noda, K.; Tojo, S.; Hisaeda, Y.; Majima, T., Phys. Chem. Chem. Phys. 2013, 15 (15), 5677-5683.

48. Shida, T., Electronic Absorption Spectra of Radical Ions. Elsevier: New York, 1988.

49. Marcus, R. A., Annu. Rev. Phys. Chem. 1964, 15, 144-196.

50. Marcus, R. A.; Sutin, N., Biochim. Biophys. Acta. 1985, 811, 265-322.

51. Holten, D.; Bocian, D. F.; Lindsey, J. S., Acc. Chem. Res. 2002, 35, 57.

52. Tsai, H.; Simpson, M. C., Chem. Phys. Lett. 2002, 353, 111.
53. Fujitsuka, M.; Shimakoshi, H.; Hisaeda, Y.; Majima, T., J. Photochem. Photobiol., A Chem. 2011, 217 (1), 242-248.

54. Cui, S.-C.; Tachikawa, T.; Fujitsuka, M.; Majima, T., J. Phys. Chem. C 2010, 114 (2), 1217-1225.

55. Takada, T.; Lin, C.; Majima, T., Angew. Chem. Int. Ed. 2007, 46 (35), 6681-6683.

56. Takada, T.; Fujitsuka, M.; Majima, T., Proc. Natl. Acad. Sci. U. S. A. 2007, 104 (27), 11179-11183.

57. Takada, T.; Takeda, Y.; Fujitsuka, M.; Majima, T., J. Am. Chem. Soc. 2009, 131 (19), 6656-6657.

58. Fujitsuka, M.; Majima, T., Photochemistry of short-lived species using multibeam irradiation. In Advances in Photochemistry, Neckers, D. C.; Jenks, W. S.; Wolff, T., Eds. Wiley: New Jersey, 2007; Vol. 29, pp 53-109.

59. Chosrowjan, H.; Taniguchi, S.; Okada, T.; Takagi, S.; Arai, T.; Tokumaru, K., Chem. Phys. Lett. 1995, 242, 644-649.

60. Andersson, M.; Davidsson, J.; Hammarstrom, L.; Korppi-Tommola, J.; Peltola, T., J. Phys. Chem. B 1999, 103, 3258-3262.

61. Fujitsuka, M.; Cho, D. W.; Shiragami, T.; Yasuda, M.; Majima, T., J. Phys. Chem. B 2006, 110 (19), 9368-9370.

62. Fujitsuka, M.; Cho, D. W.; Tojo, S.; Inoue, A.; Shiragami, T.; Yasuda, M.; Majima, T., J. Phys. Chem. A 2007, 111 (42), 10574-10579.

63. Oseki, Y.; Fujitsuka, M.; Sakamoto, M.; Majima, T., J. Phys. Chem. A 2007, 111 (39), 9781-9788.

64. Sakamoto, M.; Kim, S. S.; Fujitsuka, M.; Majima, T., J. Phys. Chem. C 2007, 111 (19), 6917-6919.

65. Dolmans, D. E. J. G. J.; Fukumura, D.; Jain, R. K., Nat. Rev. Cancer 2003, 3, 380.

66. Kawai, K.; Cai, X.; Sugimoto, A.; Tojo, S.; Fujitsuka, M.; Majima, T., Angew. Chem., Int. Ed. 2004, 43 (18), 2406-2409. 